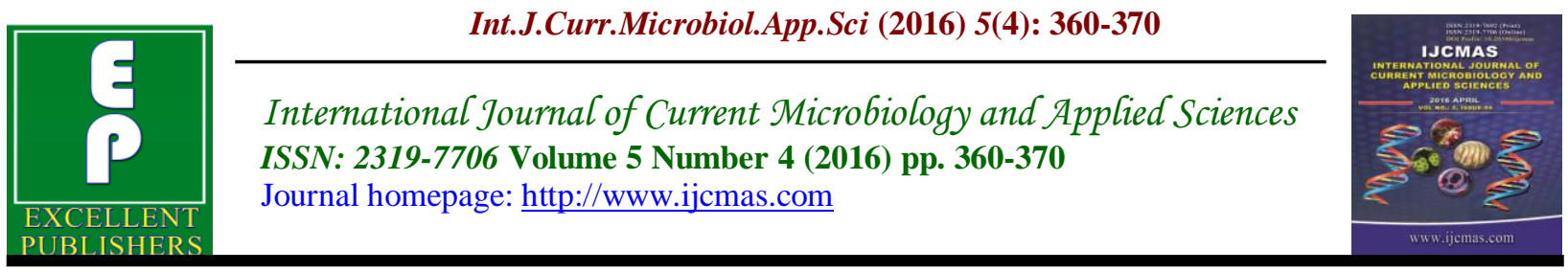

Original Research Article

http://dx.doi.org/10.20546/ijcmas.2016.504.043

\title{
Control of Chickpea Wilt caused by Fusarium oxysporum f. Sp. Ciceris with Botanical Extracts and Fungicides
}

\author{
Ekhlass Hussein Mohamed ${ }^{1 *}$, Nayla E. Haroun ${ }^{2}$ and Mawahib Ahmed ELsiddig AbdAlla ${ }^{1}$ \\ ${ }^{1}$ Department, plant protection, College of Agriculture Studies, Sudan University of Science and \\ Technology, Shambat, Khartoum State, Sudan \\ ${ }^{2}$ Department of Biology, College of Sciences \& Arts, Khafji, University of Hafr Albatin, \\ Saudi Arabia \\ *Corresponding author
}

\begin{abstract}
A B S T R A C T
Keywords

Control,

Fusarium

oxysporum $\mathrm{F}$. sp.

ciceris,

Chickpea,

Botanical

extracts,

Fungicides.

Article Info

Accepted:

20 March 2016

Available Online:

10 April 2016

A series of laboratory experiments were conducted at the Department of Plant Protection at the College of Agricultural studies- Sudan University of Science and Technology (Shambat). The objective of the study was to work out a management strategy for chickpea Cicer arietinum wilt disease caused by Fusarium oxysporum f. sp ciceri. The fungus was identified based on morphological and cultural characters as Fusarium oxysporum .In vitro studies were conducted to evaluate the effect of media, temperature and $\mathrm{pH}$ on mycelial growth of the fungus. The results showed that the fungus grew best on Potato Dextrose Agar medium $(86.7 \mathrm{~mm})$ followed by Potato Sucrose Agar $(78.2 \mathrm{~mm})$. Growth of $F$. oxysporum was maximum at 25 o C $(84 \mathrm{~mm})$ followed by $30 \mathrm{oC}(46 \mathrm{~mm})$. The maximum growth of the fungus was achieved at $\mathrm{pH} 7$ followed by $\mathrm{pH}$ 6. The antifungal effects of the medicinal plant extracts Argel (Solenostemma argel), Ginger (Zingiber officinale) and Jatropha (Jatropha crucus) (seeds, stems, leaves and roots) were determined by in vitro study using aqueous and ethanolic extracts following the Poisoned Food Technique. The extracts, undiluted and 2 and 4 -fold diluted were screened for antifungal activity using PDA medium. All extracts gave significant inhibition of growth of the pathogen. Among all plants Argel extracts was the most inhibitory. It was followed in descending order by Ginger and Jatropha. Furthermore, the ethanolic extracts of all plants was more suppressive to the fungal growth than their aqueous equivalents. The fungicides, Bayfedan, Abronstar, and Thiram each at three concentrations $(25,50$ and $100 \mathrm{ppm})$ reduced mycelial growth of the fungus in a concentration dependent manner. Thiram was the most effective (95\% inhibition) followed in descending order by Bayfidan (82\% inhibition) and Abronstar (77\% inhibition).
\end{abstract}

\section{Introduction}

Wilt disease of chickpea caused by Fusarium oxysporum f. sp. ciceris (Foc) is a complex and destructive disease all over the world. The genus Fusarium had many soil borne species which were distributed worldwide and known as plant pathogens 
since a long time ago (Moss and Smith, 1984). It is widely occurred in India (Andrabi et al., 2011), Pakistan (Hameed et al., 2012), Ethiopia (Merkuz and Getachew, 2012a), Mexico (Arvayo-Ortiz et al., 2012), Iran (Moradi et al., 2012), Nebraska, USA (Harveson 2011), Spain (Jimenez-Diaz et al., 1990), Syria (Haware 1990) and Sudan (Ali et al., 2002) where ever gram (Cicer arietinum L.) is grown.The pathogen of chickpea wilt disease is seedborne (Pande et al., 2007) as well as soil borne (Jiménez-Fernández et al., 2011). It can survive in soil for more than 6 months in damage to crop yield (Haware et al., 1986). Fusarium spreads through the soil to a small extent as mycelium. The spores or sclerotia are carried in the soil water, on farm equipment, transplants, tubers and seeds of some hosts, cuttings of infected plants and might be in some cases by windblown spores or sclerotia (Agrios, 1984). Chickpea crop is affected by several diseases but wilt caused by Fusarium oxysporum f. sp. ciceris is the most serious disease and causes heavy losses up to 10 percent in yield (Dubey et al., 2007)

The cultivars which were susceptible to chickpea wilt disease showed symptoms 25 days after sowing. The symptoms of wilt disease might be confused with root rot disease if not observed carefully. Wilted plants showed drooping and yellowing of leaves and lie down on the ground. The fungus attacked the root system, made its way through the epidermis, cortex and finally into xylem vessel of the tap root from where it spread. As a result, the lateral roots might wither off (Murumakr and Chavan 1985; Chavan et al., 2009). Resistance in available germplasm of chickpea is very uncommon and only few lines showed resistance to chickpea wilt disease so it is very important to find out other control measures against wilt pathogen. Chemical control is widely being used in past and present to cope with Fusarium wilt disease. Subhani et al. (2011) observed the effects of 6 fungicides at four different concentrations through poisoned food technique. There was a significant decrease in mycelial development of Foc pathogen with a raise in fungicidal concentration. Natural eco-system of plants also contains many beneficial microbes called symbionts. Those symbionts help plant in getting their nutrition in a better way and improve the resistance ability of the plant. Among these symbionts, two i.e. Arbuscular mycorrhizal fungi and rhizobia are very important. (Demir and Akkopru, 2007). The objectives of the current research were to successfully manage the disease with the timely use of chemicals and medicinal plants against Fusarium oxysporum f. sp.ciceris when host resistance is not available.

\section{Materials and Methods}

\section{Isolation of Fusarium oxysporum}

\section{Isolation from Plant Materials}

Infected chickpea roots showing symptoms of the disease were obtained from sick blots from Shambat Research Station in September, 2009. The roots were cut into small sections $(0.5-1.0 \mathrm{~cm})$, washed thoroughly with tap water, surface sterilized with Clorox (NaOCL) for 5 minutes, rinsed three time in changes of sterilized distilled water and dried on sterilized filter papers. The sterilized roots sections were plated at the rate of five sections/ plate onto potato dextrose agar (PDA) medium supplemented with chloramphenicol $(0.05 \mathrm{~g} / \mathrm{L})$ in $9-\mathrm{cm}$ Petri dishes. The Petri dishes were incubated at $25^{\circ} \mathrm{C}$. After incubation for 7 days, isolated fungi were subculture on PDA. When free from contamination; Isolates were maintained on PDA slants and examined 
visually for their growth patterns and pigmentation on the adverse side of the agar. Further microscopic examinations were carried out for mycelia and conidia structure using pure culture of $F$. oxysporum f.sp.ciceri was obtained by using Hyphal Tip Technique. Pure culture of the isolated fungi was transferred to PDA slants and kept in refrigerator at $40^{\circ} \mathrm{C}$ for further use. Sample of the obtained colonies were sub cultured by transferring small mycelia from the colony margins. Pure cultures were obtained by sub-culturing three times and slides were prepared and examined microscopically to confirm identity (x: 40).

\section{Isolation from Soil Sample}

Soil samples, 1gram each, were collected from the vicinity of the roots of infected plants. The samples, bulked, were thoroughly mixed and $1 \mathrm{~g}$ sample was randomly taken. The soil suspensions of different dilutions were prepared. One milliliter of each dilution was uniformly spread over PDA. The obtained colonies were sub cultured on PDA plates by transferring small mycelial from the colony margins. Pure culture was obtained by subculturing three times. The fungus was identified based on morphology and colony characteristics using the method of Watanabe (2000).

\section{Identification of the Pathogens}

The identification of the fungus was based on visual culture characteristics, mainly the growth patterns and pigmentation. Furthermore, microscopic examinations were carried out for mycelial and conidia structure based on the methods of Booth's key (1977).

\section{Growth Rate of the Pathogen}

The pure cultures of $F$. oxysporum were prepared using 7 days old mycelia. The fungus was cultured on PDA then transferred, aseptically, to the centre of Petri dishes containing PDA medium and incubated at $25^{\circ} \mathrm{C}$. The linear growth of the fungus was assessed in $\mathrm{cm}$ after $48 \mathrm{~h}$.

\section{Physiological Studies of $F$. oxysporum}

\section{Effects of Solid Media on Radial Growth of $F$. oxysporum}

Four culture media were evaluated for suitability to sustain growth of the fungus. The cultures were, Potato Dextrose Agar (PDA), Malt Extract Agar (MEA), and Czepek Dox Agar and Potato sucrose Agar (PSA). Each culture medium was prepared in 250 litre of water and autoclaved at $121^{\circ} \mathrm{c}$ for $20 \mathrm{~min}$. Three plates (9 $\mathrm{cm}$ diameters) were prepared for each medium. The plates were inoculated with $5-\mathrm{mm}$ plugs cut by a cork-borer from 7days old culture of Fusarium oxysporum. The plates were incubated at $25^{\circ} \mathrm{C}$. The fungal growth was estimated daily by measuring the colony size along the two diameters drawn on the back of each Petri dish.

\section{Effect of Liquid Media on Radial Growth of $F$. oxysporum}

Different liquid media namely Potato dextrose broth (PDB), Malt extract broth (MEB), Czepek Dox broth (CDB) and Potato sucrose broth (PSB) were evaluated for their effects on growth of $F$. oxysporum. $(250 \mathrm{ml})$, from each broth, was placed in $500 \mathrm{ml}$ flasks. Thereafter, each flask was inoculated with $5 \mathrm{~mm}$ discs cut from a 7 days old fungus culture. The treatments were replicated three times. The mycelium was retrieved from the flasks after 15 days then dry weight was measured. 
Effects of Temperature on radial $F$. oxysporum

Fusarium oxysporum, in PDA medium in Petri dishes was incubated for 7 days in the dark at different temperatures $(20,25,30$ and $35^{\circ} \mathrm{C}$ ). Each treatment was replicated 3 times. The fungus growth was measured.

\section{Effects of pH on $F$. oxysporum}

The fungus was inoculated on Potato Dextrose Broth (PDB) medium the $\mathrm{pH}$ of which was adjusted to different values (5.0, 6.0, 7.0, and 8.0). Each treatment was replicated 3 times. Flasks were inoculated with the fungus (5-mm disc) cut from7 day's old culture as in 3.2.1.The mycelium was harvested 15 days after inoculation and the dry weight was determined.

\section{Effects of Botanicals}

The aim of this experiment was to study the antifungal activities of plant extracts on the growth of $F$. oxysporum in vitro. Extracts from three plants were tested for their effects on the fungus. The plants used were Jatropha (Jatropha crucus), Argel (Solenostemma argel) and Ginger (Zingiber officinale)

\section{Sample Preparation}

\section{Collection of Plant Samples}

Jatropha crucus (leaves, seeds, roots and stems) were obtained from Sudan University of Science and Technology while leaves of Argel were obtained from the Department of Botany, Faculty of Agriculture, and University of Khartoum. Ginger was obtained from the market. All plants were cleaned from dust and strange materials by hand. The plants or the plant part were washed with tap water, air-dried under shade, and each part, packed in a separate envelope, dried in an oven at $50^{\circ} \mathrm{C}$ for $48 \mathrm{~h}$. The dried plants were crushed by a home crusher into coarse powder.

\section{Extraction Procedures}

Exactly $20 \mathrm{~g}$ of the plant material was extracted in ethanol for $48 \mathrm{~h}$ using a Soxhlet. Ethanol was evaporated using a rotary evaporator and the residues, re- dissolved in water, was stored at $58^{\circ} \mathrm{C}$ in airtight brown bottles till used. The extracts were tested for antifungal activity against Fusarium oxysporum f. sp. ciceri. Aqueous extracts of plant materials were prepared by soaking $250 \mathrm{~g}$ sample in water $(250 \mathrm{ml})$ for 4 days with occasional shaking following the procedure of Harborne (1998).

Potato Dextrose Agar (PDA) $10 \mathrm{~g}$ were placed in $250 \mathrm{ml}$ flasks. Distilled water and plant extract were adjusted to attain the respective extract dilution (undiluted, 2 and 4- foted diluted). The antibacterial Chloromycetin capsules were used to suppress bacterial contamination. Aliquots of the extract certified medium (20 ml each) was poured into sterilized glass Petri dish. After solidification of the medium, discs (5 $\mathrm{mm}$ diameter) cut from 7 days old $F$. oxysporum culture were transferred, aseptically, each placed in center of a Petri containing PDA medium for7days. The Petri dishes were incubated at $25^{\circ}$ C. Standard PDA medium without plant extracts similarly inoculated with the fungus was included as control for comparison. Each treatment was replicated three times. Treatment effects were assessed as in 3,5 and 7 days later. Percent growth inhibition was calculated using the formula developed by Jagtap and Sontakke (2007):

$$
\mathrm{I}=\frac{\mathrm{C}-\mathrm{T}}{\mathrm{C}} \times 100
$$


Where: $\mathrm{I}=$ Percent inhibition, $\mathrm{C}=$ Growth of test fungus in control medium in $\mathrm{cm}$ and. $\mathrm{T}=$ Growth of test fungus in the respective treatment in $\mathrm{cm}$

\section{Effect of Fungicides}

Three fungicides were tested in vitro to evaluate their effects on growth of the fungus employing the Poisoned food technique. The fungicides tested were Bayfidan 42, Thiram 25 and Abronstar. Three dilutions of each product were used; $0.01 \mathrm{~g}$ of each fungicide was added to $100 \mathrm{ml}$ of sterilized distilled water and was consider $100 \%$ concentration. From this concentration 2 and 4- fold dilutions were prepared by adding the required amount of sterilized PDA medium in $250 \mathrm{ml}$ conical flask to give a final respective concentration of 100,50 , and $25 \%$ of the original. The content of each flask was poured into 3 sterilized Petri-dishes and left to solidify. Subsequent to medium solidification a disc of the fungus prepared as in 3.3.3 was placed at the center of each Petri dish. Petri dishes containing standard PDA, similarly inoculated with the fungus served as control and treatment effects were assessed and calculated as.

\section{Results and Discussion}

\section{Effects of Solid Media on Radial Growth (cm) of $F$. oxysporum}

The results, showed that in the first 3 days fungal growth was similar in all media. However at seven days the redial growth of the fungus was significantly different on the different media.

The least redial growth $(7.33 \mathrm{~cm})$ was recorded on Czpecks medium, while the highest growth $(8.67 \mathrm{~cm})$ was recorded on PDA (Table 1).

\section{Effects of Broth Media on Redial Growth} (g) of $F$. oxysporum

The results indicated that the dry weight of the fungus varied greatly with the growth medium. Maximum growth of the fungus (2.44g) was achieved on PDB followed in desending order by PSB (1.95g), MED (1.78g), and Czpecks (1.25g) (Table 2).

\section{Effects of Temperature and Time on Redial Growth (cm) of $F$. oxysporum}

The fungus growth was affected by temperature and time (Fig.1). Low rate of growth was displayed at 20 OC. A surge in growth was inhibited at $25 \mathrm{oC}$ followed by a consistent decline with increasing temperature to 30 and $35 \mathrm{oC}$. The fungus growth progressively increased with time and was invariably maximal at termination (7days) of the experiment. The growth of the fungus was maximal $8.4 \mathrm{~cm}$ at $25 \mathrm{oC}$ and minimal growth was $1.36 \mathrm{~cm}$ at $20 \mathrm{oC}$

\section{Effects of pH on Redial Growth of $F$. oxysporum}

The fungus growth progressively increased with $\mathrm{pH}$ reached a maximum growth $(2.76$ g) at $\mathrm{PH} \mathrm{7,} \mathrm{and} \mathrm{then} \mathrm{declined} \mathrm{to} \mathrm{a} \mathrm{minimum}$ (1.44g) at PH 8 (Table 3).

\section{Effects of Plant Extracts on Redial Growth of $F$. oxysporum}

The results (Table 4) showed that extracts of all plants tested had negative effects on fungal growth. In general the antifungal activity increased with extract concentration. Furthermore, the ethanolic extract was invanably more effective in suppressing the fungus than its aqueous equivalent. Among the extracts tested Argel caused 66\%, 74\% and $96 \%$ inhibition of the fungus growth and was the most suppressive, followed in 
descending order by Ginger (64-72\% and 93\%inhibition) Jatropha (seeds, stems, leaves and roots)

\section{Effects of Fungicides on Redial Growth of F. oxysporum}

The fungicides Thiram, Abronstar and Bayfedan irrespective of concentration, affected significant reductions in Fusarium oxysporum growth (Table 5). The result indicated that there was a significant decrease in the mycelial growth of the fungus which progressively increased with increases concentration of the fungicide Thiram, the most effective fungicide inhibition the fungus growth effected 88,95 and $100 \%$. Abronstar resulted in 74, 82 and $100 \%$ reductions in growth whereas Bayfidan caused 70, 77 and $100 \%$ reductions in comparison to the untreated control.

The wilt of chickpea can cause considerable losses in tropical areas like the Sudan. Isolation of the fungus was carried out from wilted chickpea plants and soil collected from a sick-plot at Shambat Research Station. The identification depended on laboratory investigations. Physiological studies of chickpea wilt were made in the light of previous investigations for the effect of different culture media, temperature and pH (Kushwaha, 1971).

Four different media were used Czepek Dox Agar, malt extract Agar (MEA), Potato Dextrose Agar (PDA) and Potato sucrose Agar (PSA). The results of the experiment revealed that the PDA medium was the best for radial growth of $F$. oxysporum (86.7\%) followed by PSA medium (78.2 \%). Dikkar and Deshmukh (2003) reported similar findings. The isolates were studied for growth at different temperature levels on potato dextrose agar. The temperatures used were $20,25,30$ and $350 \mathrm{oC}$. It was observed that at $25 \mathrm{oC}$, the fungus attained the maximum growth (84 \%) followed by $46 \%$ at $30 \mathrm{o} \mathrm{C}$. This finding is consistent with that reported by Gupta et al. (1986) and is in line with the common observation that the temperature $25 \mathrm{oC}$ is the optimum for development of chickpea wilt (Chauhan, 1965). Similar results have also been demonstrated by various workers (NavasCortes et al. 2007; Bhatti and Kraft, 1992; Chi and Hansen, 1964 and Agrios, 2005). Gupta et al., (1986) also reported similar findings regarding temperature requirements by the fungus. Whereas, Chauhan (1963), Sinha and Dahiya (1973) and Desai et al., (1994) found that $25^{\circ} \mathrm{C}$ is the optimum temperature for development of Fusarium wilt. Similarly, Sharma et al. (2005) confirmed that a temperature around $25^{\circ} \mathrm{C}$ is optimum for disease development. This finding is consistent with that reported by Mina and Dubey (2010).

The isolate was studied for growth in terms of dry mycelia weight at different $\mathrm{pH}$ range viz., 5, 6, 7, and 8. Growth of the fungus was obtained at all $\mathrm{pH}$ levels tested, but it maximum at $\mathrm{pH} 7$ where it was $2.76 \mathrm{~g}$ at $\mathrm{PH}$ 6 it was $1.95 \mathrm{~g}$ and at $\mathrm{pH} 5$ it was $1.83 \mathrm{~g}$. Growth of the fungus decreased with increasing or decreasing $\mathrm{pH}$ from neutral. The results of the present study are in agreement with those achieved by Hayes (1978). However, the fungus appeared to be tolerant to a wide range of $\mathrm{pH}$ (Shaikh, 1974).

The antifungal effects of crude medicinal plant extracts Argel, Ginger and Jatropha parts (seeds, stem, leaves and root) was determined by in vitro study using water and ethanol as solvents. Three concentrations of three plants extracts were used $(25,50$, and $100 \%$ ) as antifungal activity against Fusarium oxysporum. The results of the experiment revealed that the ethanol extract was more effective than the water extract. 
Table.1 Effects of Solid Media on Redial Growth of F. oxysporum

\begin{tabular}{|l|llll|}
\hline \multirow{3}{*}{ Time/days } & \multicolumn{4}{|l|}{ Media } \\
\cline { 2 - 5 } & \multicolumn{5}{|l}{} \\
\hline 3 & PDA & MEA & PSA & CDA \\
\hline 5 & 4.17 & 3.60 & 4.16 & 3.20 \\
\cline { 2 - 5 } 7 & 7.64 & 6.23 & 6.40 & 5.15 \\
\cline { 2 - 5 } & 8.67 & 7.52 & 7.82 & 7.33 \\
\hline Lsd & .611 & .139 & .627 \\
CV\% & 8.3 & 3.8 & 4.3 & \\
CDA = Czepek Dox Agar, PDA =Potato Dextrose Agar, PSA = Potato sucrose Agar and MEA = Malt extracts \\
Agar
\end{tabular}

Table.2 Effects of Broth Media on Redial Growth (g) of F. oxysporum

\begin{tabular}{|l|llll|}
\hline Liquid Media & PDB & PSB & MEB & CZPECKS \\
\hline Dry.wieght F.oxysporum & 2.44 & 1.95 & 1.78 & 1.25 \\
\hline Lsd $(0.05)=$ & \multicolumn{3}{|c}{0.334} \\
CV\% & \multicolumn{3}{|c}{9.6} \\
\hline
\end{tabular}

$\mathrm{CDB}=$ Czepek Dox Agar, PDB =Potato Dextrose Agar, PSB = Potato sucrose Agar and MEB = Malt Extracts Agar

Table.3 Effects of $\mathrm{pH}$ on the Mycelia Dry Weight Growth of F.oxysporum

\begin{tabular}{|l|lcll|}
\hline PH & 5 & 6 & 7 & 8 \\
mycelia Dry weight /g & 1.83 & 1.95 & 2.76 & 1.44 \\
\hline Lsd (0.05) & \multicolumn{5}{|c|}{0.359} \\
CV\% & \multicolumn{5}{c|}{9.6} \\
\hline
\end{tabular}

Table.4 Effects of Plants Extracts on F. oxysporum Growth

\begin{tabular}{|c|c|c|c|c|c|c|}
\hline \multirow[t]{4}{*}{ Treatment } & \multicolumn{6}{|c|}{ Inhibition (\%) } \\
\hline & \multicolumn{3}{|c|}{ Aqueous } & \multicolumn{3}{|c|}{ Ethanol extract } \\
\hline & \multicolumn{6}{|c|}{ Dilution as of the original (\%) } \\
\hline & 25 & 50 & 100 & 25 & 50 & 100 \\
\hline Argel & $57.00 \mathrm{i}$ & $68.00 \mathrm{e}$ & $89.00 \mathrm{a}$ & $66.00 \mathrm{i}$ & $74.00 \mathrm{e}$ & $96.00 \mathrm{a}$ \\
\hline Ginger & $51.00 \mathrm{j}$ & $65.00 \mathrm{f}$ & $81.00 \mathrm{~b}$ & $64.00 \mathrm{k}$ & $72.00 \mathrm{f}$ & $93.00 \mathrm{~b}$ \\
\hline Jatropha-seeds & 40.001 & $60.00 \mathrm{~h}$ & $75.00 \mathrm{c}$ & $60.00 \mathrm{~m}$ & $67.00 \mathrm{~h}$ & $87.00 \mathrm{c}$ \\
\hline Jatropha-stems & $29.00 n$ & $51.00 \mathrm{j}$ & $72.00 \mathrm{~d}$ & $58.00 \mathrm{n}$ & 62.001 & $75.00 \mathrm{~d}$ \\
\hline Jatropha-leaves & $21.00 \mathrm{o}$ & $42.00 \mathrm{k}$ & $63.00 \mathrm{~g}$ & $55.00 \mathrm{o}$ & $54.00 \mathrm{p}$ & $71.00 \mathrm{~g}$ \\
\hline Jatropha-roots & $14.00 \mathrm{p}$ & $39.00 \mathrm{~m}$ & $57.00 \mathrm{i}$ & $44.00 \mathrm{r}$ & $49.00 \mathrm{q}$ & $65.00 \mathrm{j}$ \\
\hline Control & $0.00 \mathrm{q}$ & $0.00 \mathrm{q}$ & $0.00 q$ & $0.00 \mathrm{~s}$ & $0.00 \mathrm{~s}$ & $0.00 \mathrm{~s}$ \\
\hline $\begin{array}{l}\text { C.V\% } \\
\text { Lsd0.05 } \\
\text { SE } \pm\end{array}$ & & & & $\begin{array}{l}0.62 \% \\
0.5927 \\
0.2074\end{array}$ & & \\
\hline
\end{tabular}


Table.5 Effects of Fungicides on Redial Growth of F.oxysporum

\begin{tabular}{|l|l|l|l|}
\hline \multirow{2}{*}{ Fungicide } & \multicolumn{3}{|l|}{ Inhibition (\%) } \\
\cline { 2 - 4 } & 25 & 50 & 100 \\
\hline Thiram & 88 & 95 & 100 \\
\hline Abronstar & 74 & 82 & 100 \\
\hline Bayfedan & 70 & 77 & 100 \\
\hline Control & 0 & 0 & 0 \\
\hline Lsd(.05) $=$ & 0,396 \\
CV\% & 22.1 & \\
\hline
\end{tabular}

Fig.1 Effects of Temperature and Time on Redial Growth of $F$. oxysporum

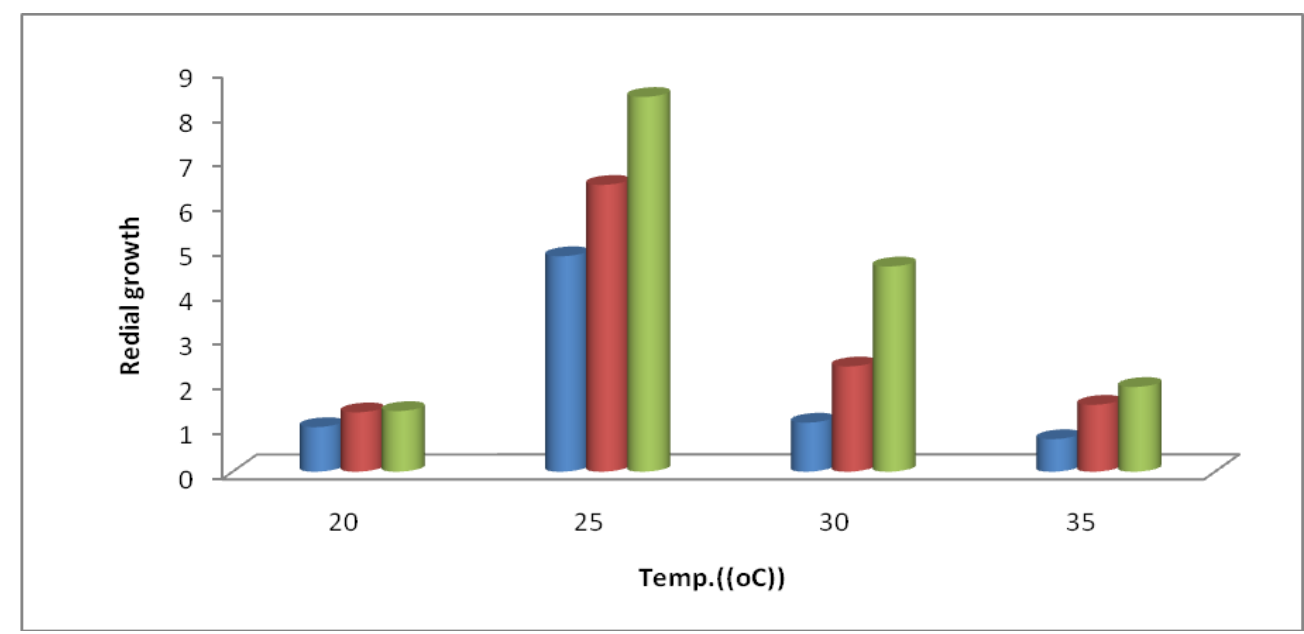

This finding corroborates the notion plant plants are one of the most important sources of medicine. Plants-derived compounds (phytochemicals) have been attracting much interest as natural alternatives to synthetic compounds.

The present investigations revealed that in vitro growth of F.oxysporum was significantly checked by aqueous extracts of Argel at all concentration. Results showed that, Argel had the highest antifungal activity against F.oxysporum as it inhibited $96 \%$ the radial fungus growth (100\%).The roots of Jatropha displaced the lowest inhibition $(65 \%)$. All the plant products tested significantly reduced the fungal growth as against radial growth in control treatment .The effect of the plant extract varied from one microorganism to another.
Our result is in agreement with the study of Agrafotis, (2002). The attributed the strong inhibitory potential of Ginger to the fact that it contains over 400 different compounds comprising of a mixture of volatile and nonvolatile chemical constituents including Zingerone, shogaols and gingerols. Abd Malek et al., (2005) investigated several essential oils from the fresh rhizomes of $\mathrm{Z}$. officinale which had high inhibitory effect on fungal growth. Our results with Jatropha are in agreement with those reported by Ogbebor et al. (2007) who showed that the J. curcas leaves extract inhibited the mycelial growth of $\mathrm{C}$. gloeosporioides in 'Para' rubber tree, while extracts of $J$. curcas stem inhibited the growth of the fungus. These finding are further supported by Igbinosa et al. (2009). 
The results on the efficacy of three fungicides tested in vitro demonstrated their significant inhibitory effect on the fungus mycelial growth. Analysis of variance showed significant interaction between concentration and reduction of mycelial growth of $F$. oxysporum as an increase in fungicide concentration decreased the mycelial growth of the fungus.

Preliminary evaluation of the comparative effect of fungicides on the mycelial growth of $F$. oxysporum revealed that the effectiveness of fungicides in inhibiting the mycelial growth of the pathogen varied.

In general an increase in fungicide concentration increased the inhibition of mycelial growth. The effectiveness of fungicides in inhibiting the growth of the fungus, in descending order was Thiram, Abronstar and Bayfedan. These results are in agreement with those of Kovacikova (1970) and Jagtap and Sontakke (2007).

\section{References}

Agrafiotis, D.K., Bone, R., Salemme, F.R. 2002. Soll R. Method of generating chemical compounds having desired properties.

Agrios, G.N. 1984. Plant Pathology, 2nd Edition, Acad. Press, NY, London.

Agrios, G.N. 2005. Environmental effects on development of the infectious disease. (in) Plant Pathology, 5th edn, Elesvier Acad. Press. Burlington, Mass, USA. pp. 251-262.

Ali, M.E.K., Inanaga, S., Sugimoto, Y. 2002. Sources of resistance to Fusarium wilt chickpea in Sudan. Phytopathol. Mediterr., 41: 163-169.

Andrabi, M., Vaid, A., Razdan, V.K. 2011. Evaluation of different measures to control wilt causing pathogens in chickpea. J. Pl. Prot. Res., 51(1): 5559.

Arvayo-Ortiz, R.M., Esqueda, M., AcedoFelix, E., Gonzalez-Rios, H., VargasRosales, G. 2012. New lines of chickpea against Fusarium oxysporumf. sp. cicer is wilt. Am. J. Appl. Sci., 9(5): 686-693.

Bhatti, Kraft, J.M. 1992. Effect of inoculum density and temperature on root rot and wilt of chickpea. Pl. Dis., 76: 960-963.

Booth, C. 1977. Fusarium Laboratory guide to the identification of the major species. Commonwealth Mycological Institute, Kew, Surrey. pp. 325.

Chauhan, S.K. 1965. The interaction of certain soil conditions in relation to the occurrence of Fusarium wilt of gram. Indian J. Agri. Sci., 35: 52.

Chauhan, S.K. 1963. Influence of different soils temperatures on the incidence of Fusarium wilt of gram (C. arietinum L.) Proc. Indian. Acad. Sci., 8: 552554.

Chavan, S.C., Hegde, Y.R., Prashanthi, S.K. 2009. Management of wilt of patchouli caused by Fusariumsolani. J. Mycol. Pl. Pathol., 39: 32-34.

Chi, C., Hassan, E.W. 1964. Relation of Temperature, $\mathrm{pH}$ and Nutrition to Growth and Sporulation of Fusarium spp. From red clover. Phytopathol., 54: 1053-58.

Demir, S., Akkoprua, A. 2007. Using of arbuscular mycorrhizal fungi (AMF) for biocontrol of soil born fungal plant pathogens. p. 17-37. In: Biological control of plant diseases. Haworth Press, USA.

Desai, S., Nene, Y.L., Reddy, A.G.R. 1994. Races of F. oxysporum causing.

Dubey, S.C., Suresh, M., Singh, B. 2007. Evaluation of Trichoderma species against Fusarium oxysporum f. sp. ciceris for integrated management of 
chickpea wilt. Biol. Cont., 40: 118127.

Gupta, S.K., Upadhyay, J.P., Ojha, K.H. 1997. Effect of fungicidal seed treatment on the incidence of chickpea wilt complex. Ann. Pl. Prot. Sci., 5: 184-187.

Hameed, A., Saddiqa, A., Nadeem, S., Iqbal, N., Atta, B.M., Shah, T.M. 2012. Genotypic variability and mutant identification in cicerarietinuml. by seed storage protein profiling. Pakistan J. Bot., 44(4):1303-1310.

Harveson, R.M. 2011. Soil borne diseases of chickpea in Nebraska. http://extension.unl.edu/ publication.

Haware, M.P., Nene, Y.L., Mathur, S.B. 1986. Seed borne diseases of chickpea.Technical bulletin Danish government institute of seed pathology for developing countries. 1: 32.

Haware, M.P. 1990. Fusarium wilt and other important diseases of chickpea in the Mediterriananean area. Options Méditerra néennes - Série Séminaires. 9:61-64.

Hayes, W.A. 1978. Nutrition, substrates and principles of disease control. In: 'The Biology and Cultivation of Edible Mushrooms', pp. 202-222. Academic press. New York

Hervastal, A., Landa, L.E., Datroff, B., Jimenez-Diaz, R.M. 1998. Effect of commercial and indigenous microorganisms on Fusarium wilt development in chickpea. Biol. Control, 13: 166-167.

Igbinosa, O.O., Igbinosa, E.O., Aiyegoro, O.A. 200. Antimicrobial activity and phytochemical screening of stem bark extracts from Jatropha curcas (Linn). Afr. J. Pharm. Pharmacol., 3: 58-62.

Jagtap, G.P., Sontakke, P.L. 2007. Management of chickpea wilt caused by Fusarium oxysporium f. sp. ciceri Afr. J. of Agric. Res., 2: 692-697.
Jimenez-Diaz, R.M., Singh, K.B., TraperoCasas, A., Trapero-Casas, J.L. 1990. Resistance in kabuli chickpea to Fusarium wilt. Pl. Dis., 75: 914-918.

Jiménez-Fernández, D., Montes-Borrego, M., Jiménez-Díaz, R.M., NavasCortés, J.A., Landa, B.B. 2011. In planta and soil quantification of Fusarium oxysporum f. sp. ciceris and evaluation of Fusarium wilt resistance in chickpea with a newly developed quantitative polymerase chain reaction assay. Phytopathol., 1(2): 250-62.

Kovacikova, E. 1970. Seed treatment of lentil and chickpea against some fungal diseases. Ochr. Rost., 6: 117126.

Kushwaha, L.S. 1971. Studies on the Physiology of Fusarium Pathogenic on Gram and Lentil. (An Annotated Biliography of chickpea diseases 1961-1976. Inform. Bull., 1: 18.

Merkuz, A., Getachew, A. 2012a. Management of chickpea wilt (Fusariumoxysporumf.sp. ciceris) using Trichodermaspp. Int. J. Curr. Res., 4(05): 128-134.

Moradi, H., Bahramnejad, B., Amini, J., Siosemardeh, A., HajiAllahverdipoor, K. 2012. Suppression of chickpea (Cicerarietinum L.) Fusariumwilt by Bacillus subtillis and Trichoderma harzianum. Plant Omic J., 5(2): 68-74.

Moss, M.O., Smith, J.E. 1984. The Applied Mycology of Fusarium. Cambridge University Press.

Murumkar, C.V., Chavan, P.D. 1985. Physiology changes in chickpea level, infected by Fusarium wilt. Biovigyanam, 11(1): 118-120.

Navas-Cortés, J.A., Landa, B.B., MéndezRodríguez, M.A., Jiménez-Díaz, R.M. 2007. Quantitative modeling of the effects of temperature and inoculum density of Fusariumoxysporum f. sp. 
ciceris races 0 and 5 on development of Fusarium wilt in chickpea cultivars. Phytopathol., 97(5): 564-573.

Ogbebor, N.O., Adekunle, A.T., Enobakhare, D.A. 2007. Inhibition of Colletotrichum gloeosporioides (Penz) Sac. Causal organism of rubber (Hevea brasiliensis Muell. Agr.) leaf spot using plant extracts. Afr. $J$. Biotechnol., 6: 213-218.

Pande, S., Rao, J.N., Sharma, M. 2007. Establishment of the chickpea wilt pathogen Fusarium oxysporum f. sp. ciceris in the soil through seed transmission. Plant Pathol., 23(1): 36.

Shaikh, M.H. 1974. Studies on wilt of gram (Cicer arietinum L.) caused by Fusarium oxysporum f.sp. ciceri in Marathwada Region. M.Sc. Thesis, Marathwada Krishi Vidyapeeth, Parbhani, India.

Sharma, K.D., Chen, W., Muehlbauer, F.J. 2005. Genetics of chickpea resistance to five races of Fusarium wilt and a concise set of race differentials for $\mathrm{F}$. oxysporum f. sp. ciceriss. Pl. Dis., 89: 385-390.

Singh, K.B., Dahiya, B.S. 1973. Breeding for wilt resistance in chickpea, in symposium on wilt problems and breeding for wilt resistance in Bengal gram. 132 September, '1973 at Indian Agriculture Research Institute, New Delhi, India, pp. 13-14(Abs.).

Subhani, M.N., Sahi, S.T., Hussain, S., Iqbal1, A.J., Hameed, K. 2011. Evaluation of various fungicides for the control of gram wilt caused by Fusarium oxysporiumf. sp. ciceris. Afr. J. Agric. Res., 6(19): 4555-4559. US Patent 6: 434,490, August 13.

Watanabe, T. 2000. Fusarium sp. Pictorial Atlas of Soil and Seed Fungi Morphologies of Cultured Fungi and Key to Species. 2nd Edn., CRC Press, New York.

\section{How to cite this article:}

Ekhlass Hussein Mohamed, Nayla E. Haroun and Mawahib Ahmed ELsiddig AbdAlla. 2016. Control of Chickpea Wilt caused by Fusarium oxysporum f. Sp. Ciceris with Botanical Extracts and Fungicides. Int.J.Curr.Microbiol.App.Sci.5(4): 360-370.

doi: http://dx.doi.org/10.20546/ijcmas.2016.504.043 